\title{
Successful treatment of visceral pseudoaneurysm after pancreatectomy using flow-diverting stent device
}

\author{
Emmanouil Giorgakis ${ }^{1,2}$, Brian Chong $^{3}$, Rahmi Oklu ${ }^{4}$, Dawn E. Jaroszewski ${ }^{5}$, \\ Grace Knuttinen ${ }^{4}$, and Amit K. Mathur ${ }^{1}$
}
${ }^{1}$ Division of Transplantation and Hepatopancreatobiliary Surgery, Department of Surgery, Mayo Clinic, Phoenix, AZ, ${ }^{2}$ Department of Solid Organ Transplantation, University of Arkansas for Medical Sciences, Little Rock, AR, ${ }^{3}$ Division of Neuroradiology, Department of Radiology, Mayo Clinic, ${ }^{4}$ Department of Interventional Radiology, Mayo Clinic, ${ }^{5}$ Division of Cardiovascular and Thoracic Surgery, Department of Surgery, Mayo Clinic, Phoenix, AZ, USA

\begin{abstract}
Aim of the study is the description of the successful management of gastroepiploic artery pseudoaneurysm with preservation of parent vessels using flow-diversion technology. The present report describes the application of a flow-diversion Pipeline $^{\mathrm{TM}}$ Flex device for occlusion of a sidewall bleeding pseudoaneurysm on a patient who was status-post sub-total pancreatectomy and remote esophagectomy with a gastric conduit. The pseudoaneurysm was on the solitary vessel supplying the patient's conduit. Use of flow diversion technology excluded the sidewall pseudoaneurysm while maintaining gastric conduit perfusion. In our case, the application of flow diversion technology allowed the preservation of patency of the main arterial supply to the gastric conduit on a post-esophagectomy patient; loss of the right gastroepiploic artery in that case would had been otherwise catastrophic. Flow-diversion technology can be considered for the treatment of pseudoaneurysms post-pancreatic resections, especially when there is no other surgical or endovascular treatment option. (Ann Hepatobiliary Pancreat Surg 2020;24:114-118)
\end{abstract}

Key Words: Gastroepiploic artery pseudoaneurysm; Flow diverter therapy; Endovascular repair visceral aneurysm; Post-pancreatectomy pseudoaneurysm

\section{INTRODUCTION}

The authors describe the successful treatment of gastroepiploic artery pseudoaneurysm with parent vessels preservation using a Pipeline ${ }^{\mathrm{TM}}$ Flex embolization device.

\section{CASE}

The patient was a 64-year old man, with remote history of trans-hiatal esophagectomy for the treatment of esophageal adenocarcinoma. 12 years later, he developed a pancreatic adenocarcinoma and was treated with subtotal pancreatectomy. His post-resection course was complicated with pancreatic leak, which precipitated intra-abdominal infection and left pleural empyema, which were drained. One-month post-resection, the patient presented with sanguineous drain output. He subsequently underwent arteriography, which revealed a pseudoaneurysm arising from the first segmental artery off the superior mesenteric artery (SMA) and the inferior pancreaticoduodenal artery anastomosing with the gastroduodenal artery and the gastroepiploic artery. The branch giving rise to the pseudoaneurysm was the only vessel supplying the gastric conduit. The pseudoaneurysm was a sidewall type associated with slow extravasation (Fig. 1), and preserved flow to the gastric conduit. Due to its small diameter, the vessel would not admit stent; vessel embolization would risk gastric conduit necrosis.

During esophagectomy, the intrathoracic, distal esophagus and proximal stomach had been removed, and the residual stomach mobilized to reach the residual esophageal stump in the neck. The gastric conduit was com-

Received: September 8, 2019; Revised: December 27, 2019; Accepted: January 19, 2020

Corresponding author: Emmanouil Giorgakis

Department of Solid Organ Transplantation, University of Arkansas for Medical Sciences, $4301 \mathrm{~W}$ Markham St. Little Rock, AR 72205, USA Tel: +1-501-686-6380, Fax: +1-501-686-5215, E-mail: EGiorgakis@uams.edu

Copyright (C) 2020 by The Korean Association of Hepato-Biliary-Pancreatic Surgery

This is an Open Access article distributed under the terms of the Creative Commons Attribution Non-Commercial License (http://creativecommons.org/ licenses/by-nc/4.0) which permits unrestricted non-commercial use, distribution, and reproduction in any medium, provided the original work is properly cited. Annals of Hepato-Biliary-Pancreatic Surgery • pISSN: 2508-5778 - elSSN: 2508-5859 
pletely dependent on blood flow from the right gastroepiploic artery (Fig. 2). It was, therefore, decided to pursue flow-diverting stent device placement across the pseudoaneurysm to preserve gastric conduit flow. The SMA was catheterized (Fig. 3). An intermediate distal access catheter (Navien 5F, Medtronic, Irvine CA) and a Phenom 027 microcatheter (Medtronic Irvine CA) were advanced over a Synchro 014 microwire (Stryker Neurovascular, Freemont CA) through the guide catheter. Attempts to advance this combination to the first order SMA branch supplying the pseudoaneurysm failed due to marked tortuosity. Angioplasty was performed and an Enterprise $4 \mathrm{~mm} \times 20 \mathrm{~mm}$ stent (Codman Neurovascular, Miami Lakes FL) was placed into the affected branch.

The patient was brought back to the interventional suite the following day for definitive treatment. Using similar technique, the SMA branch was catheterized and the micro-catheter was placed distal to the aneurysm after passing through the previously placed stent. In order to pass the microcatheter distal to the aneurysm, it was necessary to enter it with the guidewire and microcatheter and loop the system inside the aneurysm before passing out well beyond its neck, in order to deploy the flow diverter. Subsequently, a $3 \mathrm{~mm} \times 35 \mathrm{~mm}$ Pipeline Flex flow diverter (Medtronic, Irvine, CA) was delivered to the tip of the microcatheter but not deployed. The redundant loop of microcatheter was then retracted, followed by careful deployment of the Pipeline flow diverter across the pseudoaneurysm neck in the desired location. Control angiography demonstrated optimal device position but persistent vigorous filling of the pseudoaneurysm. A second Pipeline device $(3 \mathrm{~mm} \times 20 \mathrm{~mm})$ was then deployed inside the first device in a "telescoping" fashion, with demonstrated excellent stasis of contrast inside the aneurysm (Fig. 4). The patient tolerated the procedure well. He was placed on dual antiplatelet therapy. Follow-up CT angiography performed twenty months post-procedure demonstrated complete SAA exclusion with maintained patency of the Pipeline Embolization Device and inferior segmental artery. At 1-year follow-up the patient is asymptomatic and disease-free on imaging.

\section{DISCUSSION}

Even though rather uncommon, pancreatic pseudoa- neurysms can be life threatening. They develop when pancreatic secretions result in autodigestion of the adjacent arterial walls. Pancreatitis is the major pancreatic pseudoaneurysm formation cause, with an incidence as high as $10 \%$. Pancreatic pseudoaneurysms may also develop after biliopancreatic resections or after pancreas transplantation. ${ }^{1}$ The focal inflammation with or without sepsis triggered by the presence of an anastomotic leak may result in vessel erosion with pseudoaneurysm formation and delayed rupture and bleed. The splenic artery is the most frequent site of visceral artery pseudoaneurysms, followed by the hepatic artery. ${ }^{2}$

Based on the originating artery type, presence of gastrointestinal tract communication and pancreatic juice exposure, Pang et al. ${ }^{3}$ developed a management-based classification system for peripancreatic pseudoaneurysms.

Rupture carries a $13-40 \%$ mortality risk and is almost universally fatal if left untreated. Therefore, timely identification and management is of essence. Owing to interventional radiology advances, the standard of care has shifted from surgical intervention to endovascular treatment. ${ }^{4}$ Digital subtraction facilitates high resolution mapping of the peripancreatic vessels and synchronous percutaneous intervention. Pre-operative angiography allows for

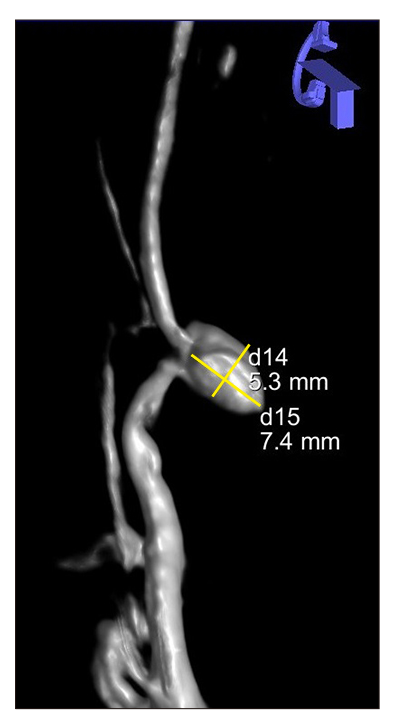

Fig. 1. 3-dimensional reconstruction of superior mesenteric artery (SMA) arteriography. The angiogram revealed a sidewall type pseudoaneurysm arising from the 1st segmental artery off of the SMA and the inferior pancreaticoduodenal artery (IPDA) anastomosing with the gastroduodenal artery and the gastroepiploic artery. The pseudoaneurysm dimensions were $5.3 \times 7.4 \mathrm{~mm}$. 


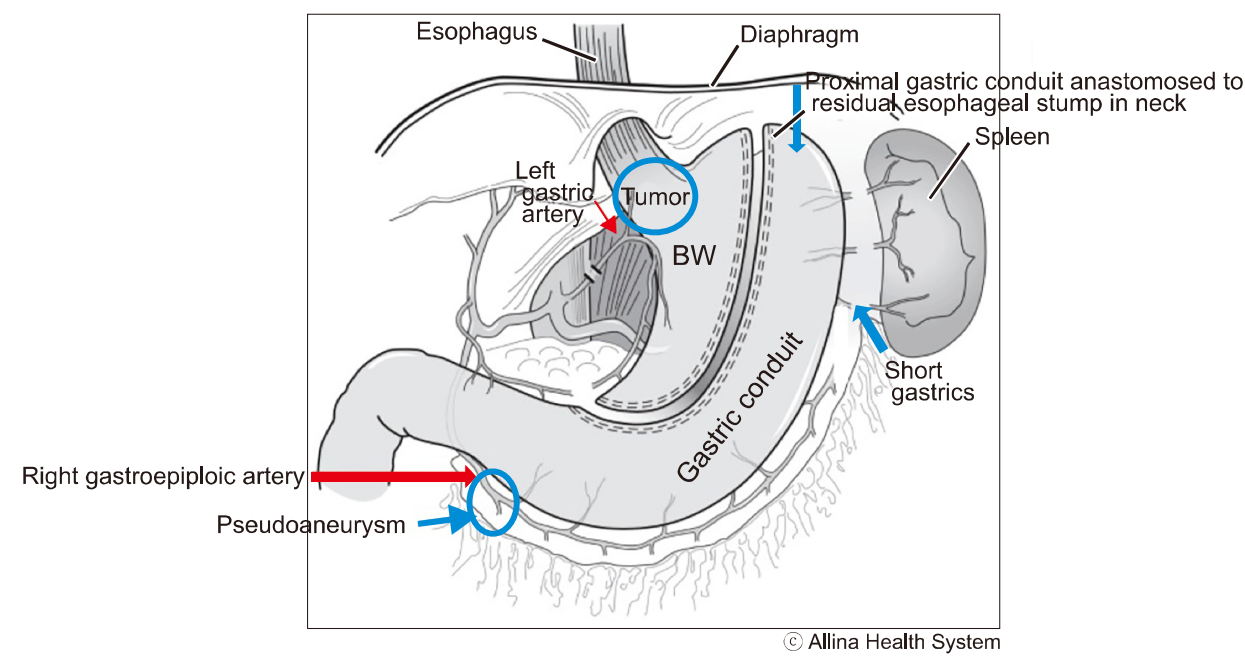

Fig. 2. Graph representation of the arterial supply of the gastric conduit. The gastric conduit was completely dependent on blood flow from the right gastroepiploic artery. The branch giving rise to the pseudoaneurysm was observed to be the only vessel supplying the gastric conduit.

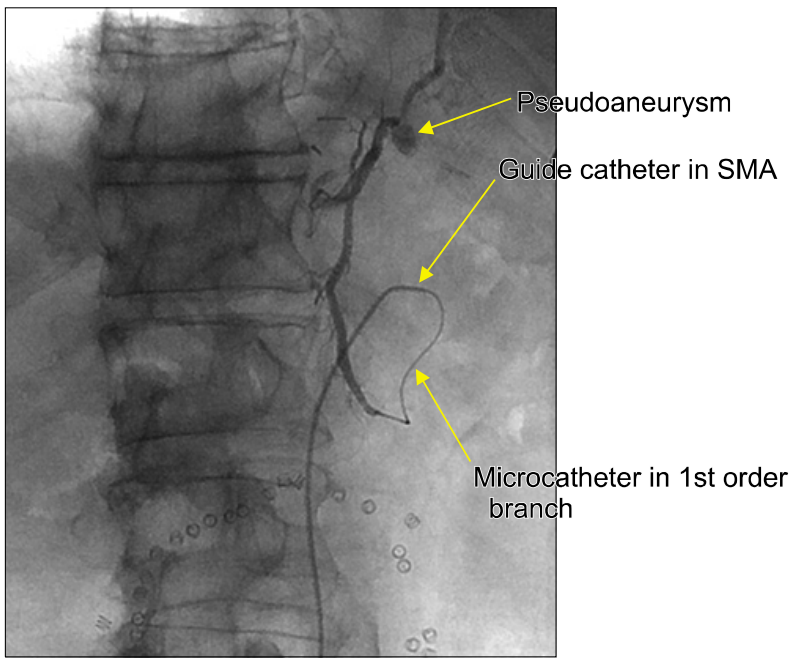

Superior mesenteric artery angiogram

Fig. 3. Superior mesenteric artery angiogram. After catheterization of the SMA, a microcatheter was advanced to the 1st order SMA branch. Injection of contrast revealed the sidewall pseudoaneurysm. This SMA branch appeared to be supplying the only vessel shown to be supplying the gastric conduit.

identification of the offending vessels and the opportunity to gain temporary control of the bleed. ${ }^{5}$

Pseudoaneurysm treatment options include endovascular coil embolization, placement of covered stent ${ }^{6}$, percutaneous thrombin injection or open surgical. Embolization is less invasive than surgical exploration and endovascular coils have been used extensively for treating visceral aneurysms. ${ }^{2,7,8}$ It is well tolerated by the patients and quick to perform. Should surgical exploration be still indicated, angioembolization would allow surgery in optimized conditions.

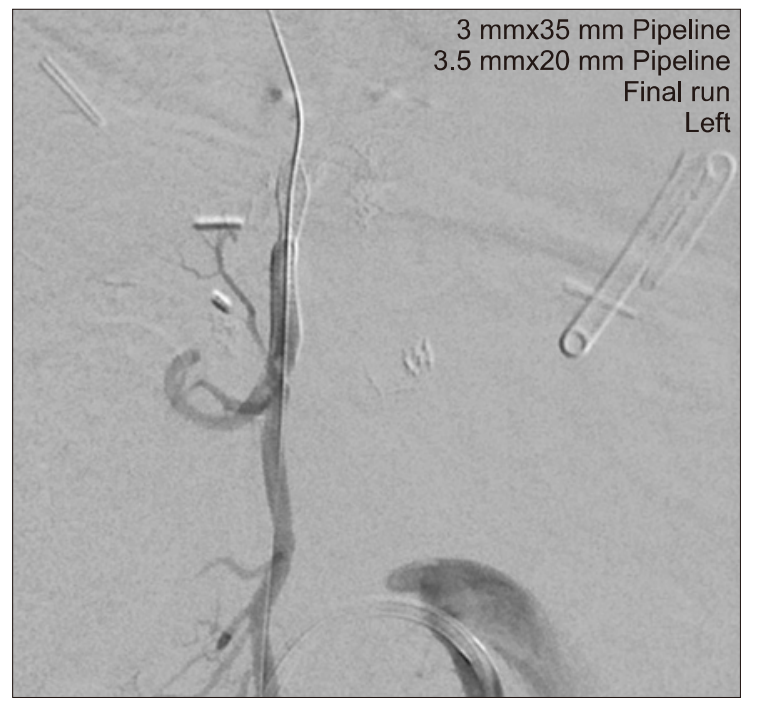

Fig. 4. Control SMA angiography post deployment of flowdiverting devices. Control SMA angiography after positioning of the first device $(3 \mathrm{~mm} \times 35 \mathrm{~mm}$ Pipeline Flex flow diverter) demonstrated optimal device position but persistent vigorous filling of the pseudoaneurysm. Deployment of a second Pipeline device $(3 \mathrm{~mm} \times 20 \mathrm{~mm})$ inside the first device in a "telescoping" fashion demonstrated excellent stasis of contrast inside the aneurysm.

The pseudoaneurysm embolization carries a reported $67-100 \%$ success rate. ${ }^{7,9}$ Its failure is usually due to inability to identify and selectively catheterize the offending vessel or misplacement of the embolization material. Possible complications are rebleeding, pseudoaneurysm rupture, arterial perforation, aortic thrombosis and bowel ischemia.

The Pipeline ${ }^{\mathrm{TM}}$ Flex Embolization device (Medtronic, Irvine, CA) is indicated for the endovascular treatment of large or giant wide-necked intracranial aneurysms. Its 
safety and efficacy in the treatment of complex intracranial aneurysms of the internal carotid artery has been assessed by the PUFs (Pipeline ${ }^{\mathrm{TM}}$ Embolization Device for Uncoilable or Failed Aneurysms), which reported 95\% occlusion at 5 years with $0 \%$ complication and $0 \%$ recurrence rates. ${ }^{10}$ Application of flow diversion Pipeline ${ }^{\mathrm{TM}}$ technology further extended in the management of posterior circulation and extracranial vertebral artery aneurysms, which would be impossible to manage with clipping or coil embolization. ${ }^{11,12}$

Despite the extensive application of Pipeline flow diversion in the management of intracranial or extracranial neurosurgical cases, its application in the abdominal visceral vasculature is extremely limited, with only a few reported applications, specifically in renal, splenic and post-transplant hepatic artery pseudoaneurysms. ${ }^{13-15}$ Adrachtas et al. $^{13}$ reported the successful use of Pipeline Embolization Device (Medtronic, Irvine, CA) for the endovascular treatment of a 40-year-old patient with a complex renal artery aneurysm. On 3-year follow-up, vascular imaging showed complete occlusion of the aneurysm and normal renal function. ${ }^{13}$ Abraham et al. reported the successful management of a symptomatic $4.1 \mathrm{~cm}$ splenic artery aneurysm (SAA) with selective two-staged segmental splenic artery embolization with the deployment of Pipeline Embolization Device (ev3 Endovascular Inc, Plymouth, Minnesota), which allowed exclusion of the aneurysm at its neck while maintaining splenic perfusion. $^{14}$

In our case, the application of PipelineTM Flex (Medtronic, Irvine, CA) flow diversion technology allowed the preservation of patency of the main arterial supply to the gastric conduit on a post-esophagectomy patient; loss of the right gastroepiploic artery in that case would had been otherwise catastrophic.

Use of flow diversion technology to occlude a bleeding pseudoaneurysm preserved the main arterial supply to the gastric conduit, in a case where there was no other surgical.

\section{ORCID}

Emmanouil Giorgakis: https://orcid.org/0000-0002-50195497

Brian Chong: https://orcid.org/0000-0001-6946-4493
Rahmi Oklu: https://orcid.org/0000-0003-4984-1778

Dawn E. Jaroszewski: https://orcid.org/0000-0002-56500691

Grace Knuttinen: https://orcid.org/0000-0001-5772-119X

Amit K. Mathur: https://orcid.org/0000-0002-9215-2014

\section{AUTHOR CONTRIBUTIONS}

Conceptualization: BC, AKM. Data curation: BC, DEJ, GK, RO. Writing - original draft: EG. Writing - review \&amp; editing: AKM, RO, GK, BC.

\section{REFERENCES}

1. Lubezky N, Goykhman Y, Nakache R, Kessler A, Baruch R, Katz $\mathrm{P}$, et al. Early and late presentations of graft arterial pseudoaneurysm following pancreatic transplantation. World J Surg 2013;37:1430-1437.

2. Harvey J, Dardik H, Impeduglia $T$, Woo D, DeBernardis $F$. Endovascular management of hepatic artery pseudoaneurysm hemorrhage complicating pancreaticoduodenectomy. J Vasc Surg 2006;43:613-617.

3. Pang TC, Maher R, Gananadha S, Hugh TJ, Samra JS. Peripancreatic pseudoaneurysms: a management-based classification system. Surg Endosc 2014;28:2027-2038.

4. Shrikhande GV, Khan SZ, Gallagher K, Morrissey NJ. Endovascular management of superior mesenteric artery pseudoaneurysm. J Vasc Surg 2011;53:209-211.

5. Jain G, Kathuria S, Nigam A, Trehan VK. Transcatheter embolization of a giant pancreatic pseudoaneurysm: a tale of two bleeds and one thrombus! Indian Heart J 2013;65:91-94.

6. Onizawa S, Hamano M, Tsuchiya A, Araida T, Toda J, Yamamoto M. Successful treatment of pseudoaneurysm rupture after pylorus preserving pancreaticoduodenectomy by covered stent placement. Surg Technol Int 2012;22:77-82.

7. Radeleff B, Noeldge G, Heye T, Schlieter M, Friess H, Richter GM, et al. Pseudoaneurysms of the common hepatic artery following pancreaticoduodenectomy: successful emergency embolization. Cardiovasc Intervent Radiol 2007;30:129-132.

8. Won Y, Lee SL, Kim Y, Ku YM. Clinical efficacy of transcatheter embolization of visceral artery pseudoaneurysms using N-butyl cyanoacrylate (NBCA). Diagn Interv Imaging 2015;96: 563-569.

9. Hyare H, Desigan S, Nicholl H, Guiney MJ, Brookes JA, Lees WR. Multi-section CT angiography compared with digital subtraction angiography in diagnosing major arterial hemorrhage in inflammatory pancreatic disease. Eur J Radiol 2006;59:295-300.

10. Becske T, Kallmes DF, Saatci I, McDougall CG, Szikora I, Lanzino G, et al. Pipeline for uncoilable or failed aneurysms: results from a multicenter clinical trial. Radiology 2013;267: 858-868.

11. Awad AJ, Mascitelli JR, Haroun RR, De Leacy RA, Fifi JT, Mocco J. Endovascular management of fusiform aneurysms in the posterior circulation: the era of flow diversion. Neurosurg Focus 2017;42:E14.

12. Dolati P, Eichberg DG, Thomas A, Ogilvy CS. Application of pipeline embolization device for iatrogenic pseudoaneurysms of the extracranial vertebral artery: a case report and systematic re- 
view of the literature. Cureus 2015;7:e356.

13. Adrahtas D, Jasinski P, Koullias G, Fiorella D, Tassiopoulos AK. Endovascular treatment of a complex renal artery aneurysm using coils and the pipeline embolization device in a patient with a solitary kidney. Ann Vasc Surg 2016;36:291.e5-291.e9.
14. Abraham RJ, Illyas AJ, Marotta T, Casey P, Vair B, Berry R. Endovascular exclusion of a splenic artery aneurysm using a pipeline embolization device. J Vasc Interv Radiol 2012;23:131135. 